\title{
Laboreal
}

Volume $4 \mathrm{~N}^{\circ} 1$ | 2008

Ergologia, trabalho, desenvolvimentos

\section{Um projecto de pesquisa : O trabalho informal : um objecto ergológico?}

\section{Fyad Abderrahmane}

Tradutor. Liliana Cunha e Marianne Lacomblez

\section{(2) OpenEdition \\ Journals}

\section{Edição electrónica}

URL: http://journals.openedition.org/laboreal/12206

DOI: 10.4000/laboreal.12206

ISSN: 1646-5237

\section{Editora}

Universidade do Porto

\section{Refêrencia eletrónica}

Fyad Abderrahmane, «Um projecto de pesquisa : O trabalho informal : um objecto ergológico ? », Laboreal [Online], Volume $4 \mathrm{~N}^{0} 1$ | 2008, posto online no dia 01 julho 2008, consultado o 23 setembro 2020. URL : http://journals.openedition.org/laboreal/12206 ; DOI : https://doi.org/10.4000/laboreal. 12206

Este documento foi criado de forma automática no dia 23 setembro 2020.

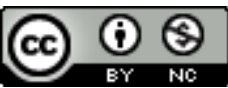

Laboreal está licenciado com uma Licença Creative Commons - Atribuição-NãoComercial 4.0 Internacional. 


\title{
Um projecto de pesquisa : 0 trabalho informal : um objecto ergológico?
}

\author{
Fyad Abderrahmane \\ Tradução : Liliana Cunha e Marianne Lacomblez
}

A ergologia poderia dizer do trabalho informal que é desobediente, indisciplinado.

2 Mas antes de abordar os aspectos que interpelam e questionam este posicionamento intelectual, considera-se, previamente, a importância de um ponto de vista quantitativo.

\section{Alguns dados quantitativos sobre a importância do trabalho informal nos países ditos em desenvolvimento (países do Sul)}

3 O trabalho informal é um fenómeno vivido a céu aberto nos países do Sul. Ele é animado por uma população geralmente jovem: adolescentes acabados de sair do circuito escolar, quando ele existe, ou por jovens que ainda não trabalharam. Ele ocupa percentagens muito elevadas da população activa, nomeadamente nos grandes centros urbanos. Certas estatísticas, em África e na Índia [ $\left.{ }^{1}\right]$ avançam números, entre $40 \% \mathrm{e}$ $60 \%$ da população, como vivendo essencialmente de uma actividade comercial, de serviço ou agrícola informais.

4 Na Argélia, hoje o fenómeno é facilmente observável nos centros urbanos de todas as dimensões.

5 A venda de fugida, a venda de cigarros avulso, a venda de saquinhos no mercado, a guarda de automóveis nos espaços públicos, a venda de água doce, de pão "caseiro", a recuperação de objectos usados, a venda de lixívia, as bancas de bombons, a venda de frutos, de legumes e mesmo de carne não controlada pelo veterinário, fazem parte deste cenário em nítida progressão. 
6 Neste país de 32 milhões de habitantes, a taxa de desemprego roça, apesar de uma queda importante, os 15,3\% em $2004{ }^{[2]}$ e $70 \%$ deste potencial activo tem menos de trinta anos.

7 A aplicação nos anos 1994 e 1995 do PAS [3] provocou uma importante sangria no sector público. Não menos de 400.000 empregados pagaram as despesas desta terapia de choque [4] e engrossaram as listas dos desempregados [5].

8 Estas populações são potencialmente candidatas a um recrutamento pelo sector informal.

9 Na Argélia este sector ocuparia até $40 \%$ do mercado de trabalho [ [ $]$.

10 Com efeito, este fenómeno não poupa nenhum país, nenhuma comunidade. Os mesmos países da OCDE [?] alojam-no, com estimativas de 11 \% para a Irlanda e a Nova Zelândia, $19 \%$ na Alemanha e $20 \%$ no sector industrial na Itália.

11 Este lugar preponderante que ocupa o trabalho informal na actividade de vida e ou de sobrevivência de milhões de pessoas independentemente do seu peso sobre as economias dos países e as consequências políticas e sociais que decorrem ou que o alimentam justifica amplamente o interesse que se lhe pode atribuir.

\section{0 trabalho candidato à abordagem ergológica ?}

12 Os esforços de várias disciplinas académicas para o circunscrever (abordagem jurídica do direito, socioeconómica da sociologia e da economia) fracassam ao defini-lo ou têm um sucesso apenas parcial [8]. Esta incompletude é desconcertante [ $\left.{ }^{9}\right]$, mas tem sem dúvida a sua fonte no facto do trabalho informal ser analisado a partir de campos disciplinares concebidos para outros usos.

13 Ele é então considerado como o outro pólo de um continuum predefinido pelo trabalho formal e torna-se uma forma degradada, desnaturalizada, fora da lei. Esta abordagem, curiosa no plano epistemológico, está provavelmente subjacente à vontade de torná-lo um objecto integrável dos saberes sábios, dos conhecimentos académicos.

14 As abordagens desenvolvidas partem do modelo [10 ${ }^{10}$ do trabalho assalariado (contrato, subordinação, direito do trabalho, ...), historicamente constituído, e não da actividade real, viva, que o alimenta, lhe dá forma e permite com efeito conhecê-lo realmente, de o definir com os seus actores no quotidiano, obter um conhecimento que pode fazer património, enriquecido a partir dos saberes investidos que tem as norias ${ }^{[1]}$ do mundo dos "pequenos ofícios" e do "desenrasque".

15 A sua incomensurabilidade coloca problemas às políticas, às instituições, aos Estados : não é dominável, é insubmisso (à fiscalidade), é não planificável (progride de acordo com leis que parecem relevar do caos), é não integrável (nos programas de saúde e de formação) ; mas a sua existência é salvadora (desempenha um papel de amortecedor inigualável para absorver o descontentamento popular e o desemprego de facções inteiras da sociedade, dos jovens em particular, nomeadamente nos países do Sul). A sua irredutibilidade a qualquer ponto de vista tem de igual apenas o seu papel de auxiliar a economias em sofrimento nos países pobres ou "disfuncionais". 


\section{A ergologia e as nossas hipóteses de trabalho} actividades informais e o que procuram elas ? O ganho mais ou menos fácil ? A fonte de saciedades ainda honestas (roubos, crimes são sentidos fortemente como concomitantes à frequência elevada do trabalho informal) das necessidades vitais de subsistência? Eles procuram ainda outra coisa, para além da aparência fortemente condenável das actividades parasitárias?

a normas exteriores; submeter-se às instruções, sacrificar-se às tradições, obedecer às regras da profissão. $O$ trabalho impõe portanto: disciplina; enquadramento do comportamento, repressão da satisfação imediata. Nada de tudo isto caracteriza à primeira vista o envolvimento dos actores que se implicam no trabalho informal. No entanto, fora do quadro estatutário preexistente, próprio ao trabalho formal, a actividade do agente "informal" comporta as mesmas características ou até os mesmos ingredientes de competência que, por exemplo, perante um ofício a tecer.

Os seus actores possuem "uma bagagem mínima sobre o seu ofício", gostam também do trabalho bem feito, acolhem favoravelmente o reconhecimento do "cliente", pertencem a redes $\left.{ }^{[12}\right]$ de relações corporativas, de apoio, de entreajuda ou de defesa, aspiram a desenvolver-se. 
25 A actividade no sector formal é um lugar de renormalização de normas antecedentes onde o sujeito ultrapassa o simples papel do executante que obedece, para se descobrir actor que age activamente e criador. No trabalho informal, devido à ausência de normas antecedentes formalmente identificáveis, será a actividade um outro género de trabalho: uma actividade primitiva, natural, vital, de subsistência, de sociabilidade - ou mesmo associal ? Não estará a actividade em acção para gerar normas ainda não elaboradas ? Não estará ela em luta, encostada à fortaleza ainda inexpugnável do mundo do trabalho informal pelo menos nos sectores que lhe conferem a permissividade do Direito oficial dos Estados? Não será ela produtora de normas antes da hora?

Ou então, as suas normas não seriam as proibições que a penalizam (regulamentos, opiniões desfavoráveis, artigos de imprensa denunciadores, multas, apreensão de bens, ...) ?

Mas a situação particular onde se manifesta a actividade do trabalho informal não é a anomia total : ela é caracterizada necessariamente por regras gerais irredutíveis como : a existência de produtos mercantis e os seus preços, os serviços prestados e os seus custos, até às regras mais gerais que emprestam à ética (confiança) ou ao comércio (concorrência). Encarada assim, parece que podemos falar a propósito da actividade informal de necessidades de renormalização, tal como este termo é definido no e aquando do trabalho stricto sensu [13].

Aqui, o sujeito assemelha-se mais ao camponês face ao seu

campo que ao trabalhador numa cadeia de montagem. Certamente o camponês é também mais ou menos constrangido por múltiplas contingências naturais (clima, hidrometria, química dos solos...) e sociais (custos, confiança, reputação, ...) ; mas em certos aspectos é mais ou menos livre das suas escolhas quanto ao plano de cultura, ao tipo de semente, à ordem de colocação na terra.

31 Da mesma forma o sujeito (trabalhador) do trabalho informal move-se num quadro social que funciona de acordo com regras que o obrigam apenas parcialmente. Lá deve encontrar o seu lugar, exercer a sua actividade e fixar-lhe limites que somente o seu interesse parece governar [ ${ }^{14}$ ]. Ele é mais o seu próprio produtor, o seu próprio juiz das normas e limites a que se deve submeter do que o trabalhador "formal".

32 Ele está perante um duplo constrangimento : onde há ausência de normas, ele tem que as produzir e logo negociá-las (ao uso e às respostas induzidas) para as modificar se necessário : ele renormaliza então as suas próprias normas [15].

No fim de contas, o aprofundamento da actividade manifesta-se como abertura a um tipo de trocas que não pode ser interpretado sobre o modo da troca exclusivamente mercantil. o sujeito descobre-se capaz de dar mais do que o que era esperado.

O trabalho informal não seria então uma forma de terapia social inconsciente contra as ameaças psicológicas inerentes ao desemprego, tanto quanto uma libertação da tirania das exigências de satisfação imediata e uma abertura à construção de um mundo comum?

Jovens, adultos ou adolescentes, não fazem uma construção simultânea da sua pessoa através da actividade emancipadora de um ofício escolhido e criado por eles? 


\section{Metodologia prevista no âmbito do projecto de investigação}

O objectivo : realizar uma pesquisa o mais próxima possível das actividades do trabalho informal numa grande metrópole argelina.

As actividades visadas são seleccionadas devido à existência de investigações que se relacionam com elas : guarda de automóveis, a venda de fugida, venda ambulante de água doce, a venda de saquinhos pelas crianças, o escoamento de portáteis (roubados), a venda de cigarros.

38 O contrato de investigação : a abordagem não é prisioneira da urgência do resultado esperado, da aplicação imediata de soluções que impõe a abordagem ergonómica; o único contrato é de ordem científica e ética mas no que diz respeito a um mundo que não pede nada e que desenvolve mesmo uma atitude contraditória face ao interesse que se lhe pode manifestar : ele vive mal a indiferença das instituições e desconfia a priori de todas as abordagens incluindo as cientificas de que retém apenas a palavra "inquérito" no sentido prosaico do termo.

Os princípios éticos e metodológicos : a franca explicação e as provas de sinceridade e honestidade do investigador que, uma vez que adquirida a adesão, abre áreas de colaboração e de participação inanticipáveis à partida ; os inquéritos junto dos actores realizados por uma equipa de investigadores (cada um cobre um segmento das actividades informais retidas) que recorrem à observação do trabalho sobre o terreno em contexto real (na rua, no bairro, diurno e nocturno...), à observação participante (sempre com o acordo dos sujeitos observados), à filmagem, à entrevista ; questionários e entrevistas são reservados aos institucionais (juízes, jornalistas, universitários, imãs, ...) no que respeita à definição, ao papel e às opiniões sobre o trabalho informal.

\section{NOTAS}

1. O conceito é atribuído a: Hart, K. (1973). Informal income opportunities and urban employment in Ghana. Journal of Modern African Studies, II.

2. Heuze, G. (1987). Notas relativas à mão-de-obra do sector informal na Índia dos dias de hoje. Economies en transition - Bulletin de liaison, 9/10.

3. Heuze, G. (1987). Notas relativas à mão-de-obra do sector informal na Índia dos dias de hoje. Economies en transition - Bulletin de liaison, 9/10.

4. Índices estimados: Banque Mondiale (2005). ICT at a glance. Algérie.

5. PAS: Programa de Ajustamento Estrutural divulgado pelo Banco Mundial e o Fundo Monetário Internacional.

6. Banque Mondiale (2004). Rapports sur l'Algérie.

7. O desempregado é definido pela ONS (Serviço Nacional das Estatísticas da Argélia) como: "qualquer pessoa que durante o período de referência não trabalha (não se encontra ocupado), procura trabalho, está em idade de trabalhar (16 a 60 anos) e disponível para trabalhar". 
8. Nabila, O. (1975). Le travail informel: le parcmètre humain. Mémoire pour l'obtention du diplôme d'études médicales spéciales de médecine du travail, sous la direction de Fyad Abderrahmane. Oran: Faculté de Médecine.

9. Organização de cooperação e de desenvolvimento económico.

10. Ver nomeadamente: Sethurman, S.V. (1990). Urban poverty and the informal economy. Maryland: University of America; Mazumbar, D. (1976). The Urban Informal Sector. Royaume Uni: World bank staff working paper.

11. CIST/OIT (2003). 17ème Conférence Internationale des Statistique du Travail.

12. Charmes, J. (2000). Définition et évolution du secteur informel. Université de Versailles SaintQuentin-en-Yvelines: Centre d'économie et d'éthique pour l'environnement et le développement. 13. Péraldi, M. (2002) (Dir.). La fin des norias? Réseaux migrants dans les économies marchandes en méditerranée. Paris: Éditions Maison Neuve et Larose.

14. As redes comerciais da Confraria Tidjania da África do Oeste são disso um exemplo.

15. Schwartz, Y. \& Durrive, L. (2003) (Dir.). Travail et Ergologie: entretiens sur l'activité humaine. Toulouse: Octarès.

\section{AUTORES}

\section{FYAD ABDERRAHMANE}

Faculté de médecine d'Oran - Université d'Oran Service de médecine du travail - EHU Oran abfyad@yahoo.fr 